\title{
Alcohol effects on variability-contingent operant responding in the rat
}

\author{
LOWELL T. CROW \\ Western Washington University, Bellingham, Washington
}

\begin{abstract}
Male albino rats were trained by autoshaping in a two-bar operant for water reinforcement. A behavioral variability reinforcement contingency was then imposed in which variations in an unrestricted four-response sequence were required. LAG- 5 contingencies (in which response sequences over the previous five sets could not be repeated) produced reliably high uncertainty scores, which were easily reversed by impositions of stereotypic response-reinforcement contingencies. Compared with saline-injected controls, subjects receiving i.p. injections of ethanol $(0.5 \mathrm{~g} / \mathrm{kg})$ were found to show an increased uncertainty of responding in the LAG-5 contingency condition. In that previous findings suggest a decrease in uncertainty of responding under stereotypic contingencies, it is proposed that a drug variability-contingent dependency exists that may shed light on the brain mechanisms of behavioral variability.
\end{abstract}

Crow (1982) found that low and moderate doses $(0.5-1.2 \mathrm{~g} / \mathrm{kg})$ of alcohol reduce behavioral variability in terms of uncertainty of response sequences in the rat's performance on a simple two-bar alternation problem. This finding is in keeping with previous findings of reduced behavioral variability in rat's behavior (Crow, McWilliams, \& Ley, 1979).

Although reinforcement ordinarily promotes diminished behavioral variability, Page and Neuringer (1985) showed that variability itself may be subject to reinforcement contingencies. Pigeons were reinforced by food only if an unrestricted eight-response sequence was not repeated. Under these conditions, the uncertainty of responding was not significantly different from formula-generated random sequences.

The present study was designed to attempt to replicate Page and Neuringer's (1985) results with rats using water reinforcement, and to investigate the effects of alcohol on behavior controlled by variable reinforcement contingencies.

\section{METHOD}

\section{Subjects}

Eleven locally bred male albino rats were used as subjects. The animals ranged in age from 90 to 150 days at the beginning of the experiment. The 6 younger animals were experimentally naive, and the older 5 had been shaped to a single-bar water-reinforced operant 3 months previously.

\section{Apparatus}

A Gerbrands two-bar operant chamber, modified for water delivery, was used in conjunction with an Atari $800 \mathrm{XL}$ computer used both for programming contingencies and for data collection and analysis.

\section{Alcohol Doses}

Ten minutes prior to the session, a $10 \%$ aqueous solution of $95 \%$ ethanol was injected i.p. in an amount that was $0.5 \mathrm{~g} / \mathrm{kg}$.

Address correspondence to Lowell T. Crow, Department of Psychology, Western Washington University, Bellingham, WA 98225.

\section{Procedure}

The 6 younger animals were put on a $231 / 2-h$ water-deprivation regimen and autoshaped to the two-bar response using a procedure modified from that of Page and Neuringer (1985). At varying intertrial intervals, averaging $20 \mathrm{sec}$, one of two lights above each bar was randomly illuminated for $3 \mathrm{sec}$. This was followed by a 3-sec reinforcement. Barpressing during the periods in which the lights were illuminated were reinforced immediately. Sessions terminated after the 60 th reinforcement. After 2 days on this schedule, the autoshape program was modified so that automatic (without barpressing) reinforcement followed the lighted side only $50 \%$ of the time. The older 5 animals, already shaped to a single-bar operant, were placed into the two-bar chambers later with no prior exposure.

After pressing was autoshaped (see the Results section for autoshape failures), a LAG-1 contingency was imposed in which a four-response sequence of presses (in any pattern) was reinforced only if the sequence was altered from the last. A subsequent LAG-2 contingency was imposed after 1 week ( 5 working days), and the final LAG- 5 contingency was imposed 1 week ( 5 working days) later. A session consisted of either 20 min duration or a 250 response total, at which time uncertainty scores were computed and collected on a printer. All animals received $30 \mathrm{~min}$ of free water in addition to that obtained during the daily experimental sessions.

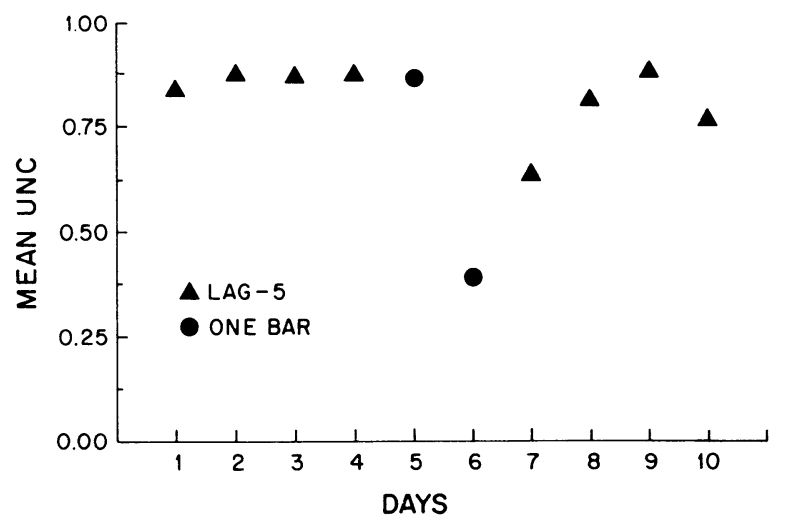

Figure 1. Mean uncertainty scores for the LAG-5 and single bar (SBR) reinforcement contingencies. 


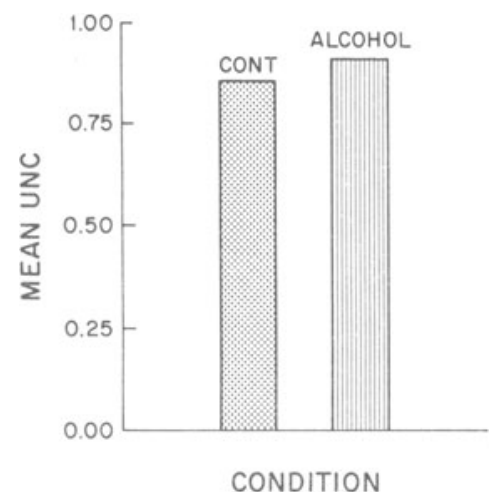

Figure 2. Mean uncertainty scores for the placebo (CONT) and ethanol (ALCOHOL) conditions.

After a stable level of uncertainty scores was attained, a stereotypic single-bar-right contingency was imposed for 2 days, followed by a return to the LAG-5 condition. When uncertainty scores had again stabilized, alcohol treatments were begun. Treatments consisted of either ethanol or saline injections $10 \mathrm{~min}$ prior to the daily session.

\section{RESULTS}

Three of the 6 animals given autoshaping did not acquire the response within a 2 -week period and were discarded from the study. Two of those animals trained earlier on a single-bar operant did not acquire the LAG5 contingency response.

The initial LAG-5 contingency data as well as the singlebar-right (SBR) and subsequent LAG-5 contingency data are presented in Figure 1. It can be seen that the response, reflected by the U-data to the differing reinforcement contingencies, was both rapid and robust.

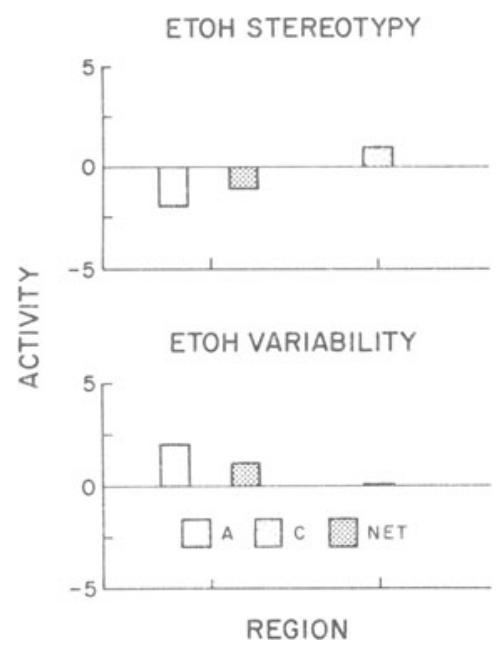

Figure 3. Hypothesis of the differing effects of alcohol upon stereotypic and variability reinforcement contingencies. See text.
The low dose of alcohol $(0.5 \mathrm{~g} / \mathrm{kg})$ appeared to increase the uncertainty of responding (Figure 2), this being the case when the U-values were already high. The mean alcohol uncertainty was 0.905 , and the control $U$-value was $.851[F(5,4)=5.131]$.

\section{DISCUSSION}

In keeping with the results of Page and Neuringer (1985), the present study indicates that behavioral variability, as measured by two-bar responding, can be made contingent upon reinforcing stimulation. The changes in behavioral variability corresponding to the changes in reinforcement contingencies were similar to those obtained using response rate as a measure. These findings are consistent with those of Page and Neuringer (1985) using pigeons with an eight-response sequence to two pecking disks. Also in keeping with Page and Neuringer (1985), the results suggest that memory of the previous response segments is not required, but that a central behavioral variability generator may be activated.

The differences between alcohol's effects on these reinforcement contingent variabilities and its effects on those employing stereotypic reinforcement contingencies may shed light on the brain mechanisms involved. Crow (1985) suggested that alcohol may exert its stereotypic effects either by direct inhibition of the cerebral cortex (A), the presumed variability generator, or by an inhibition of subcortical inhibitory influences (C) upon the cerebral cortex. Either effect would account for the reduced variability seen with traditional (stereotypic) reinforcement contingencies, but neither would account for the increased variability seen with variability-contingent reinforcement.

A possible explanation is as follows: if alcohol produces a relatively greater inhibition of system $A$ than system $C$, and if there is a relatively greater mobilization of the $\mathrm{C}$ system than the A system with stereotypycontingent reinforcement and, conversely, a relatively greater mobilization of the A system than the $\mathrm{C}$ system in case of variability-contingent reinforcement, alcohol may produce differing effects depending on the two situations. Figure 3 depicts these events.

Say that alcohol produces twice as much depression of the cortex (A) as of the subcortical inhibitory system (C). Assume, in addition, that stereotypy-contingent reinforcement results in twice as much activity in the subcortical systems (C) as in the cortex (A). The resultant effects on alcohol on the stereotypy-contingent behavior would be a net -1 . If there is greater cortical activation than subcortical activation (e.g., three times) in the variability contingent situation, then the net effect of alcohol would be +1 .

Alcohol is an irregularly spreading depressant (Goodman \& Gillman, 1960 ), and one might expect that in low doses it differentially affects the cerebral cortex. Lesions of the cortex do diminish behavioral variability (Crow \& McWilliams, 1979), and small lesions within the substantia nigra do not eliminate the alcohol-stereotypy effect (Crow \& Spring, 1984).

Conditioning phenomena have been localized in subcortical areas (Thumpson, 1980), and the assumption that stereotypy-contingent reinforcement may involve relatively greater activity there than in the cortex appears warranted. The assumption that variability-contingent behavior requires a much greater cortical than subcortical role also seems indicated by the evidence.

\section{REFERENCES}

CROw, L. (1982). Ethanol-induced response stereotypy: Simple alternation, fixed-interval rates of response, and response location. Bulletin of the Psychonomic Society, 19, 169-172.

Crow, L. (1985). More on variability as a behavioral concept. The Psychological Record, 35, 293-300.

Crow, L., \& McWilliams, L. (1979). Relative stereotypy of wateringestive behavior induced by frontal cortical lesions. Neuropsychologia, 17, 393-400. 
Crow, L., McWilliams, L., \& Ley, M. (1979). Relative stereotypy of water-ingestive behavior induced by chronic alcohol injections in the rat. Bulletin of the Psychonomic Society, 14, 278-280.

Crow, L., \& SPRING, W. (1984, May). Effects of substantia nigra lesions in the rat on ethanol-induced reduction of behavioral variability. Paper presented at the meeting of the Pacific Cascade Chapter of the Society for Neuroscience, Timberline Lodge, OR.

Goodman, I., \& Gillman, A. (1960). The pharmacological basis of therapeutics. New York, NY: MacMillan.
Page, S., \& Neuringer, A. (1985). Variability is an operant. Journal of Experimental Psychology: Animal Behavior Processes, 11, 429-452. Thompson, R. F. (1980). The search for the engram, II. In D. McFadden (Ed.), Neural mechanisms of behavior (pp. 172-222). New York: Springer-Verlag.

(Manuscript received for publication July 20, 1987.) 